\title{
A REVOLUÇÃO CUBANA: REPRESENTAÇÕES GENERIFICADAS EM UM LIVRO DIDÁTICO DE HISTÓRIA ${ }^{1}$
}

\author{
Andréa Mazurok Schactae ${ }^{2}$
}

\begin{abstract}
Resumo: O artigo é uma análise das representações da Revolução Cubana em um manual didático de História, edições de 2013 e 2016, produzido para o ensino médio e utilizado no Campus do IFPR de Telêmaco Borba. Para problematizar o texto, foram consideradas algumas produções historiográficas sobre a Revolução Cubana e textos publicados nos primeiros anos da Revolução, entre 1959 e 1965. A categoria gênero é central na análise das representações presentes no manual, considerando que os manuais são construtores de consciência história, a partir de J. Rüsen. Portanto, a partir de J. Scott, R. Chartier, J. Courtine e R. Connel foi problematizada a representação da Revolução Cubana, presente no manual didático, observando os sujeitos silenciados pela representação e dialogando com o conceito de virilidade.
\end{abstract}

Palavras-chave: Representações sociais. Revolução Cubana. Ensino de história. Livro didático. Gênero.

\section{THE CUBAN REVOLUTION: GENDERED REPRESENTATIONS IN A HISTORY TEXTBOOK}

\begin{abstract}
This article reports an analysis of the representations of Cuban Revolution in the 2013 and 2016 editions of a history textbook targeted for the highschool and used in the IFPR Campus in the city of Telêmaco Borba. With the purpose of problematizing this text, it was considered some historiographical productions on the Cuban Revolution and texts published in the early years of the Revolution, between 1959 and 1965. The category of gender is central in the analysis of the representations present in the textbook, considering that those books are builders of historic conscience, according to J. Rüsen. Therefore, following J. Scott, R. Chartier, J. Courtine and R. Connel, it was problematized the representation of Cuban Revolution as it is presented in those textbooks, highlighting the subjects that were silenced by this representation, and discussing the concept of virility.

Keywords: Social representations. Cuban Revolution. Teaching of history. Textbook. Gender.

\section{LA REVOLUTION CUBAINE: LES REPRESENTATIONS GENREES DANS UN MANUEL SCOLAIRE D'HISTOIRE}

Résumé: Cet article est une analyse des représentations de la Révolution cubaine dans un manuel scolaire d'histoire, éditions de 2013 et 2016, produit pour l'enseignement secondaire [lycée] et utilisé sur le campus de l'IFPR [Institut fédéral du Paraná] de Telêmaco Borba. Pour problématiser le texte, on a examiné certaines productions historiographiques sur la Révolution cubaine et des textes publiés dans les premières années de la Révolution, entre 1959 et 1965. La catégorie du genre est centrale dans l'analyse des représentations présentes dans le manuel, considérant qu'elles sont bâtisseuses de conscience historique, d'après J. Rüsen. Ainsi, partant de J. Scott, R. Chartier, J. Courtine et R. Connel, la représentation de la Révolution cubaine présente dans le manuel a été mise en perspective, en observant les sujets tus par la représentation et en dialoguant avec le concept de virilité.

Mots-clés: Représentations sociales. Révolution cubaine. Enseignement de l'histoire. Manuel scolaire. Genre.

\footnotetext{
${ }^{1}$ A primeira versão desse texto foi apresentada no $6^{\circ}$ Simpósio Eletrônico Internacional de Ensino de História, realizado por meio da plataforma: www.simpohis2020.blogspot.

${ }^{2}$ Professora de História do Instituto Federal do Paraná (IFPR); professora do Mestrado Profissional em História, na UEPG; Coordenadora do Grupo de Estudos Cultura, Identidades e Gênero, no IFPR; Coordenadora do NEABI, Campus IFPR Telêmaco Borba. Pesquisa sobre gênero em instituições armadas e Revolução Cubana.
} 


\section{LA REVOLUCIÓN CUBANA: REPRESENTACIONES GENERIZADAS EN UN LIBRO DIDÁCTICO DE HISTORIA}

\section{Resumen:}

El artículo colo el análisis de las representaciones de la Revolución Cubana en un Manual didáctico de Historia, ediciones de 2013 y 2016, producido para la enseñanza media y utilizado en el Campus del IFPR de Telémaco Borba. Para problematizar el texto se tomaron como referentes algunas producciones historiográficas sobre la Revolución Cubana y textos publicados entre 1959 y 1965, años iniciales de la Revolución. La categoría género es central en los análisis de las representaciones presentes en el Manual, considerando que los manuales son constructores de conciencia histórica, a partir de J. Rüsen. Desde los referentes de J. Scott, R. Chartier, J.Courtine y R. Connel, fueron problematizadas las representaciones de la Revolución Cubana contenidas en el Manual, colocando énfasis en los sujetos silenciados en estas y dialogando con el concepto de virilidad.

Palabras clave: Representaciones sociales. Revolución cubana. Enseñanza de la Historia. Libro didáctico. Género.

\section{Introdução}

O livro didático de história faz parte do dia a dia nas salas de aula e influencia na construção de uma memória histórica, sendo assim o objetivo desse texto é identificar as representações sobre a Revolução Cubana, em um livro didático de história, utilizando os conceitos de consciência histórica (RÜSEN, 2001; 2010), de representações (CHARTIER, 1990) e da categoria de análise gênero (SCOTT, 1995). O livro didático que foi selecionado é utilizado pelos estudantes do ensino médio, do Campus do Instituto Federal do Paraná (IFPR), em Telêmaco Borba. E para verificar possíveis alterações no texto sobre a Revolução Cubana, foram comparados os textos de duas edições do livro, referentes aos anos de 2013 e 2016.

O olhar para a Revolução Cubana foi uma escolha devido a permanência desse acontecimento, que marcou a história do século XX na América Latina, nas memórias do Ocidente na atualidade, bem como pela construção de uma memória que vincula a Revolução com a imagem de homens barbudos, vestindo fardas e com armas. Uma memória que projeta uma representação generificada, que reproduz uma ordem na construção dos Estados no Ocidente, cujos espaços de poder são domínio de homens.

Vale destacar, que ao longo do tempo se constituem percepções sobre a história do Estado e as suas organizações de poder, como espaços estabelecidos e ocupados por homens. Portanto, assim como os Estados Modernos, a Revolução Cubana construiu os seus símbolos e suas práticas como identificadores de um ideal de masculinidade 
(CONNEL, 2005), o qual é caracterizado pela virilidade ${ }^{3}$. Os heróis estabelecidos seguem a tendência ocidental e são percebidos por suas práticas identificadoras da virilidade. Homens que pertenceram a instituições armadas e participaram de conflitos armados, são constituídos em símbolos identificadores do Estado.

Voltando o olhar para a construção dos símbolos nacionais e instituições armadas, observa-se que os heróis, se constituem em representações de um ideal de masculinidade (SCHACTAE, 2013; MOREIRA, 2015; BONINO, 2002; STONER, 2003; OLAVARRIA, 2001; CONNEL, 2005). Destarte, a farda e as armas, são construções simbólicas que ao longo do tempo se tornaram em identificadores do poder do Estado e de uma masculinidade viril, identificada pela violência, pela força, pela coragem, pela honra e pela dominação de sujeitos que são percebidos como superior a outros sujeitos.

A representação do poder, marcada por características viris, é herdada da longa duração (COURTINE, 2013), e ainda está presente em instituições que constituem o estado - forças armadas, parlamento, polícia -, portanto, é parte de identidades e práticas generificadas, que orientam o estabelecimento de um "saber a respeito das diferenças sexuais" (SCOTT, 1994, p. 12). Esses saberes, entre os quais a virilidade, são percebidos em práticas, símbolos, leis e narrativas sobre o passado do Estado e de suas instituições. Também são percebidos nos livros didáticos de história e na historiografia.

Para Abel Sierra Madero (2006),, a historiografia cubana, tende a explicar os processos históricos focando na guerra, que é percebida como um espaço pertencente e identificador de um ideal de masculinidade. Portanto, para o pesquisador, os estudos da História de Cuba, sobre a perspectiva da guerra, reforçam um modelo de cubania heterossexual, patriarcal, sexista e homofóbico (SIERRA MADERO, 2006, p. 68).

Em Cuba, e em outros lugares do Ocidente, conforme destaca Ariel Sierra Madero (2005), entre o final do século XVIII e as primeiras décadas do século XIX, está se construindo uma nação-sexuada imaginada, os Estados Nacionais silenciam as mulheres e colocam os homens heterossexuais no domínio do lugar público (CORBIN,

\footnotetext{
${ }^{3}$ Virilidade para George Vigarello, Alain Corbin, Jean-Jacques Courtine é um ideal, cujas qualidades que compõe o que é viril são reconstruídas ao longo do tempo. O ideal viril de uma sociedade militar é diferente de uma sociedade mercantil, porém são marcados por ideias de coragem, força e domínio sexual. Portanto, a virilidade como: "o conjunto de papéis sociais e dos sistemas de representações que definem o masculino e também o feminino não pode se reproduzir, enquanto tais, senão se a hegemonia virial aparecer como pertencente à ordem natural e inelutável das coisas" (COURTINE, 2013, p. 8).
} 
2013; SIERRA MADERO, 2006). Os mambises ${ }^{4}$ que lutaram pela independência de Cuba do domínio espanhol, são representados na historiografia como heróis, homens e heterossexuais (SIERRA MADERO, 2006, p. 85).

Essa herança cultural que constitui as culturas, no Ocidente, também é percebida na Revolução Cubana. Um acontecimento que marcou o século XX e exportou um ideal de masculinidade para a América Latina. Para Matías Alderete (2013, p. 3), a construção do homem novo, pela Revolução Cubana, é constituída pela "masculinidade revolucionária" e marcada pela homofobia. Prevalece em Cuba o modelo do macho, porém, "un macho no es homosexual ni heterosexual per se, sino la continua muestra de valores masculinos: ser violento y agresivo, hablar y actuar en forma vulgar y penetrar en la relación sexual" (ALDERETE, 2013, p. 6). Para a Revolução o contrarrevolucionário é o maricon, isto é, aquele que é penetrado e apresenta comportamento percebido como feminino (ALDERETE, 2013, p. 6-7), pois o homossexual macho tendia a ser aceito como macho revolucionário, nas décadas de 1960 e 1970, em Cuba.

Orientando-se por esse modelo de cubania, constituído por um ideal de macho revolucionário, a Revolução Cubana é um movimento paradoxal, pois, ao mesmo tempo que se propõe estabelecer uma ruptura na ordem estabelecida político-econômico-social, ela também ressignificou um ideal de masculinidade na segunda metade do século XX, ao construir uma representação do guerrilheiro, marcada por um ideal viril. Os guerrilheiros representam a força, a coragem e a vitória de um ideal político, portanto uma revolução caracterizada pelo viril.

Além do mais, as memórias sobre a Revolução tendem a silenciar os sujeitos que fogem ao padrão de masculinidade viril. Alguns sujeitos são mais silenciados que outros, pois as mulheres guerrilheiras, ocupam um espaço na memória - um exemplo a obra Marianas: nobleza y coraje, de N. Escalona Rodríguez (2018) -, porém sujeitos que não incorporam o guerrilheiro tendem a ser silenciados.

Portanto, os significados das diferenças historicamente construídas para os sexos, podem ser percebidos: nos símbolos; nos discursos; nas práticas; nas representações; nas identidades; nos espaços sociais. Ao orientar a construção dos espaços sociais, o gênero também dá significado as relações de poder (SCOTT, 1995, p. 88). E, sendo a história um saber, ela também é constituída pelo gênero, orientando a

\footnotetext{
${ }^{4}$ Mambises é a denominação dada aos movimentos armados anti-espanhóis (CUERVO ALVAREZ, 2016, p. 91). "Mambises. Combatentes da independência cubana" (CHOMSKY, 2015, p. 290).
} 
construção de representações sobre as realidades e práticas sociais, bem como de subjetividades e as memórias.

Considerando essa construção da cubania, analisada pela historiografia que problematiza as questões de gênero, é importante observar os livros didáticos, por serem instrumentos de construção da consciência histórica. Para J. Rüsen (2010), a consciência histórica é:

[...] como a atividade mental da memória histórica, que tem sua representação em uma interpretação da experiência do passado encaminhada de maneira a compreender as atuais condições de vida e a desenvolver perspectivas de futuro na vida prática conforme a experiência. (RÜSEN, 2010, p. 112)

Sendo assim, voltar o olhar para os manuais didáticos é importante para desconstruir as representações do passado, orientadas pelo protagonismo masculino, pois a consciência histórica orienta a construção de subjetividades. E construir reflexões sobre as representações do passado, presentes nos manuais didáticos é um passo que pode possibilitar a construção de uma memória histórica que possa descontruir o ideal de masculinidade viril como significado de poder.

E para identificar as representações da Revolução Cubana, os livros didáticos são analisados a partir das concepções de análise de conteúdo de L. Bardin (2011), da análise do discurso, orientando-se pela categoria gênero (SCOTT, 1995), e dialogando com o conceito de representações (CHARTIER, 1990). Vale destacar, que na análise de imagens é realizado um diálogo com autores que utilizam imagens como fonte histórica.

Nos esforços de compreender as imagens, P. Burke (2004, p. 226) concorda com Maria Mauad (1996), ao compreender que é uma tarefa que exigem um diálogo transdisciplinar, que recebeu a influência da sociologia, da história da arte, da antropologia, da filosofia, etc. e, conforme destaca o autor, esse diálogo é enriquecido com as análises de gênero. E, ao se focar no estudo dos significados em relação ao contexto, as visões dos contemporâneos da imagem e as entrelinhas (BURKE, 2004, p. 236-238), não há uma receita ou um método certo para os estudos da história a partir de imagens, que produzem representações.

\section{Revolução Cubana e gênero: alguns apontamentos}

A Revolução Cubana, iniciada em meados do século $\mathrm{XX}$, tende a ser apresentada como um espaço de atuação política de homens armados e uma herança das guerras do século XIX. Vale lembrar que, em 10 de março de 1952, Fulgencio Batista 
liderou um golpe de Estado e estabeleceu uma ditadura, em Cuba, a qual durou até 1959. Em primeiro de janeiro de 1959, o Exército Rebelde, apoiado por outros movimentos de oposição à ditadura - entre os quais: Federação dos Estudantes Universitários, Movimento 26 de Julho, Partido Democrata, Partido do Povo Cubano, Resistência Cívica, Frente Cívica de Mulheres do Centenário Martiniano, Mulheres Oposicionistas Unidas, e outras -, entrou em Havana, encerrando o processo de luta armada da Revolução. Portanto, a vitória foi resultado de uma união de vários movimentos em torno do Movimento 26 de Julho e do Exército Rebelde (CHOMSKY, 2015; AYERBE, 2004; PAGÉS, 1991). Todavia, produções historiográficas (FERNANDES, 2007; AYERBE, 2004; LOPEZ; LOYOLA; SILVA, 2005; GROTT, 2006) tendem a destacar a luta armada como central para o processo e na construção dessa interpretação alguns fatos históricos e espaços são significativos.

Sendo assim, o ataque ao Quartel Moncada, em 26 de julho de 1953, é percebido como marco do processo revolucionário, seguindo as memórias da Revolução, construídas pela imprensa cubana, em 1959 (MISKUIN, 2003; BEAUDIEU, 2013), e posteriormente pelo Estado Cubano. Também a historiografia tende a ser influenciada pelo mito da Sierra Maestra, lugar que os guerrilheiros se estabeleceram após o desembarque do Granma - barco que trouxe o grupo de guerrilheiros do México, os quais iniciaram a luta armada, em 1956. Apropriando-se desses acontecimentos, as memórias da Revolução, vinculam a luta armada da década de 1950 como herdeira das guerras da Independência do século XIX, colocando a luta armada como central na construção do Estado Cubano.

Ao analisar as guerras da Independência em Cuba, em 1868 e 1895, Sierra Madero (2006), indica que a construção de narrativas sobre a história de Cuba, aumentou durante o período de guerras. Os diferentes atores sociais que participaram da guerra construíram discursos sobre os acontecimentos, entre os quais a construção do Mambí, a representação do homem rebelde que luta pela liberdade da colônia.

Todavia, a imagem do Mambí foi construída durante os primeiros anos da República, a partir do ano de 1902, e devido a crescente influência norte-americana, nas políticas do Estado Cubano (SIERRA MADERO, 2006). Ao analisar os diários de guerra, o historiador observa que muitos sujeitos foram silenciados na história da nação, entre esses silêncios está o lugar secundário dado para as mulheres no processo de independência. A imagem da nação foi construída a partir de um modelo masculino viril e heterossexual (SIERRA MADERO, 2006, p. 53-72). 
Essa herança generificada presente na construção da identidade nacional Cubana tende a silenciar o outro (aqueles que não correspondem ao ideal de homem cubano) e rememorar o modelo de homem viril e heterossexual. Uma herança que norteia a construção de políticas do Estado Cubano, na década de 1960, com a criação das Unidades Militares de Ayuda a la Producción (UMAP), para as quais foram enviados homossexuais e outros indesejáveis sociais (SIERRA MADERO, 2006, p. 197). Sujeitos que estavam as margens da construção do homem novo, estabelecido pelo projeto revolucionários da década de 1960.

Essa valorização de determinados sujeitos, está presente nos primeiros escritos sobre a História da Revolução Cubana, entre os quais se destacam os textos do médico, Ernesto Guevara - que no processo revolucionário se tornou um guerrilheiro e assumiu o nome de Ernesto Che Guevara, o Che. O guerrilheiro Che Guevara, foi constituído, na década 1960, em um mito que encarna o ideal de homem viril e passou a identificar a Cuba revolucionária. Os seus textos: "Uma história da Revolução Cubana", publicado na Revista Cruzeiro, no Brasil, em 1959 (GUEVARA, 1959); e "O socialismo e o homem em Cuba", publicado em 1965, no Uruguai (GUEVARA, 1965), são marcos significativos na construção de uma narrativa sobre a História da Revolução Cubana, que coloca a guerrilha como central.

O texto publicado em 1959, por Ernesto Che Guevara, pode ser lido como fundante do mito da Revolução dos Guerrilheiros, sendo a guerrilha e os guerrilheiros os sujeitos da vitória. O movimento urbano é esquecido, bem com os movimentos que antecederam o Movimento 26 de julho ${ }^{5}$ - esse Movimento foi criado após o ataque ao Quartel Moncada, em 1953 - e a participação das mulheres na guerrilha. No outro texto, publicado em 1965, ele segue com essa construção discursiva, ao colocar o Estado, o Partido e os homens de vanguarda - os guerrilheiros -, como encarregados de educar o povo para o socialismo (GUEVARA, 1965). Sendo assim, ele define quem foram os sujeitos que construíram e legitimam a Revolução Cubana. Ao afirmar que no dia 26 de julho de 1953, "um grupo de homens dirigidos por Fidel Castro atacou [...] o Quartel Moncada" (GUEVARA, 1965), ele oculta a presença de mulheres nesse grupo, e legitima a Revolução como um espaço de homens que pegaram em armas para defender um projeto político.

\footnotetext{
${ }^{5}$ Estudo sobre movimentos sociais em Cuba (LEYVA PAGÁN, 2009), sobre o movimento estudantil (PEREZ ROJAS, 1975) e sobre o movimento clandestino urbano (GRAÑA EIRIZ, 2008).
} 
Nos discursos de Fidel Castro, publicados pelo Departamento de Orientación Revolucionária del Comité Central del Partido Comunista de Cuba, em 1978, a história de Cuba é uma história de lutas, iniciadas no ano de 1868, e realizadas por homens, que se uniram contra o imperialismo (CASTRO, 1978). E em entrevista com Ignacio Ramonet, ele reafirma que o início da Revolução Cubana é marcado pela primeira guerra da Independência, em 1868 (RAMONET, 2006, p. 42-43). Essa narrativa coloca os guerrilheiros, do século $\mathrm{XX}$, como herdeiros dos mambis, os guerrilheiros do século XIX. Assim, os acontecimentos do passado são importantes para legitimar a Revolução Cubana.

Vale destacar que os textos de Che Guevara, também fortalecem uma projeção internacional desse acontecimento que marca a história política do século XX, ao serem publicados fora de Cuba. Nos dois textos, o autor destaca a luta armada e os líderes homens como centrais na construção o projeto político revolucionário em Cuba. Portanto, as armas, os homens e a guerra representam o núcleo central para compreender o processo revolucionário e da vitória dos rebeldes. O ideal de masculinidade, construído por esses textos e somados a herança cultural estabelecida pela República Cubana, no início do século XX, orientou a construção de um modelo de revolucionário pela Revolução Cubana. O guerrilheiro, barbudo, heterossexual e viril, é o modelo estabelecido e que norteia as políticas de Estado, que exclui os vistos como indesejáveis.

Portanto, os textos de Fidel e Che Guevara projetam um ideal de cidadania, a qual também é um ideal de masculinidade caracterizado pela virilidade. Além do que, esses líderes homens se constituem em guias e salvadores do povo (GIRARDET, 1987). Uma construção discursiva produzidas pelos revolucionários e que também está presente na historiografia.

Na obra sobre a Revolução Cubana, de Florestan Fernandes, publicada pela primeira vez em 1979, o nacionalismo cubano é percebido como resultado do processo de independência, que uniu diferentes grupos sociais, contra um inimigo comum, o imperialismo (FERNANDES, 2007, p. 90). Para ele, a independência é uma conquista de um movimento de luta de guerrilheiros contra o imperialismo, bem como a Revolução Cubana. Portanto, a revolução da década de 1959 é explicada pelo que ele identifica como "espírito guerrilheiro", pois: 
[...] O 'espírito guerrilheiro' teria de inspirar um partido revolucionário criado depois da conquista do poder e, o que era mais complexo, deveria delimitar até onde chegaria a revolução cubana através do novo Estado, da nova sociedade e do novo homem. [E] [...] a atividade legislativa e executiva que o exército rebelde forjou construía o espírito revolucionário do guerrilheiro dentro da ação. (FERNANDES, 2007, p. 127; 132).

Nessa leitura apresentada por Florestan Fernandes, identifica-se uma influência das ideias presentes nos textos do Ernesto Che Guevara. E, ao eleger o guerrilheiro como central para compreender a Revolução Cubana, o autor coloca as figuras de Che Guevara e o Fidel Castro, como os líderes da guerrilha e da revolução. Vale destacar, que o autor faz uma referência a presença de mulheres na guerrilha (FERNANDES, 2007, p. 130), porém o espírito guerrilheiro pertente aos homens.

Para Aviva Chomsky - em seu livro de título "História da Revolução Cubana", publicado em 2015 -, a memória e a historiografia sobre a Revolução Cubana tendem a colocar a atuação da guerrilha, como central para o processo revolucionário. A luta armada na Sierra Maestra, ocupa o lugar central para compreender o sucesso da Revolução, bem como a guerrilha é identificada como herdeira dos ideais revolucionários do processo de Independência, no século XIX. Portanto, a Revolução é percebida como uma aplicação dos ideais da independência. E a guerrilha é o sujeito que herda esses ideais, pois:

O Movimento 26 de Julho queria levar a cabo o projeto pelo qual José Martí e tantos outros haviam morrido. Em 1898, as forças de ocupação norteamericanas impediram que o exército rebelde de Cuba entrasse na capital de Santiago (CHOMSKY, 2015, p. 46).

Essa ideia está presente no texto publicado por Ernesto Che Guevara, em 1959. E está presente também na análise do pesquisador Luis F. Ayerbe (2004), pois, para ele, “a revolução de 1959 tem profundas raízes na trajetória histórica nacional, com antecedentes que remontam ao período independentista" (AYERBE, 2004, p. 21). Em todas as obras citadas, a guerrilha é o sujeito central da Revolução.

Para os historiadores cubanos, Francisca López, Oscar Loyola e Arnaldo Silva (2005), a Revolução é um processo de libertação nacional das influências do capitalismo e do imperialismo norte-americano (LOPEZ; LOYOLA; SILVA, 2005, p. 223-228). Portanto, é observada como um processo resultante de uma conjuntura política e social, que remonta a meados do século XIX e a luta armada é central nas narrativas sobre a Revolução da década de 1950. A atuação das mulheres na Revolução Cubana é silenciada pelos autores cubanos, bem como por Aviva Chomsky (2015). 
Embora Aviva apresente uma historiografia que questiona o protagonismo da guerrilha e coloca o movimento urbano como fundamental para o processo (CHOMSKY, 2015, p. 46), os homens seguem sendo os protagonistas da Revolução.

Ao apresentar uma nova história de Cuba, Richard Gott (2006), tende a destacar a atuação dos homens como centrais para a Revolução Cubana. O capítulo - Revolução de Castro toma forma 1953-1961 - (GOTT, 2006, p. 171-217), o autor coloca Fidel Castro como o protagonista do processo e também indica que os rebeldes do século XX são herdeiros daqueles do século XIX (GROTT, 2006, p. 185). Ao se referir ao ataque ao Quartel Moncada, em Santiago de Cuba, ocorrido em 26 de julho 1953, ele silencia a presença das mulheres no processo, mas faz referência à atuação de Haydée Santamaria nesse acontecimento, em outro momento do texto.

Vale destacar que Haydée Santamaria e Melba Hernandes atuaram no transporte das armas, de Havana para Santiago de Cuba, bem como no planejamento e ataque ao quartel. Também foram presas, assim como os demais sobreviventes do ataque, conforme relatos de Melba, que lembra que, além delas, outras mulheres participaram da organização e planejamento do ataque (ILISÁSTIGUI AVILÉS; ÁLVAREZ PORRO, 2005; SCHACTAE, 2016).

Ao relatar a chegada do jornalista do New York Times, Herbert Matthews, na Sierra Maestra, bem como o processo de busca pelo apoio de outras organizações contrárias a ditadura de Batista, Richard Gott destaca a atuação de Haydée e então a coloca como uma "veterana de Mondaca" (2006, p. 181; 186). Outras mulheres citadas pelo autor são: Célia Sanchez, Vilma Espin e Aleida March. A Célia é identificada como "leal colaboradora" (GOTT, 2006, p. 188) de Fidel Castro. Vilma é lembrada por suas atividades políticas em Santiago de Cuba, como "filha do advogado da Bacardi" (GOTT, 2006, p. 185), e também como aquela que se tornou a esposa de Raul Castro, bem como Aleida figura como a esposa de Ernesto Che Guevara (GOTT, 2006, p. 193). Portanto, embora o autor inove ao colocar mulheres como sujeitos da Revolução Cubana, nomeando essas mulheres, elas ainda são identificadas como esposas e/ou filhas.

Elas são retiradas do protagonismo político e vinculadas aos nomes de homens, que se tornaram heróis da Revolução ou figuras importante no Estado Cubano, a partir dos anos de 1960, - Fidel Castro, Armando Hart, Ernesto Guevara, Raul Castro. E embora elas sejam nomeadas pelo autor, elas não são nomeadas como guerrilheiras. Os homens seguem sendo os guerrilheiros nas narrativas da história da Revolução Cubana. 
Ao olhar para textos publicados dentro e fora de Cuba, observa-se que embora alguns rompam com a memória, que coloca a guerrilha e os homens como responsáveis pelo processo revolucionário, ainda permanece a tendência de reproduzir uma interpretação marcada pela afirmação do guerrilheiro como protagonista. A atuação dos outros movimentos sociais e das mulheres tende ser silenciada.

\section{A Revolução Cubana em livros didáticos}

O conhecimento do discurso de algumas obras historiográficas sobre a Revolução Cubana é fundamental para análise do livro didático selecionado, pois permite perceber se existe de um diálogo entre a produção historiográfica e os textos didáticos. E, voltando o olhar para as representações da Revolução Cubana nos livros didáticos no Brasil, destaca-se o texto de Rafael Adão e Julio Cesar dos Santos (2015). Ao ser realizada uma pesquisa na plataforma Google sobre o tema "livros didáticos e Revolução Cubana", o silêncio é quebrado apenas por esse texto. No qual os autores analisam as narrativas sobre a Revolução Cubana, focando nas relações políticas em Cuba e no contexto internacional, indicando as aproximações entre os textos dos livros didáticos e algumas obras historiográficas sobre a Revolução Cubana.

Sendo assim, ainda está em aberto à construção de uma reflexão sobre as representações da Revolução Cubana nos livros didáticos, utilizando como ferramenta de análise a categoria gênero. E retomando a ideia de que os manuais didáticos orientam a construção de uma consciência história (RÜSEN, 2010), é fundamental uma reflexão sobre os discursos generificados presentes nessas ferramentas do ensino de História.

Ao se identificar o livro didático como construtor de sentido, cabe uma análise dos sentidos que estão sendo apresentados nos livros didáticos, sobre a Revolução Cubana. A importância do livro didático para o ensino é destaca por Itamar Oliveira e Margarida Oliveira (2014), pois "coerente com o valor atribuído ao ensino de História (enraizado na matriz disciplinar - objeto da sua teoria da História), o livro didático é visto como instrumento fundamental para a vida escolar, já que atua, diretamente, na construção do sentido (orientação no tempo)" (OLIVEIRA, 2014, p. 227). E, ao construírem sentido orientam a constituição da consciência histórica. Portanto, as representações presentes nos livros didáticos contribuem para construção da consciência histórica dos estudantes.

Este trabalho entende que as representações são formas de percepção do social que produzem discursos e práticas que buscam legitimar ou justificar para os próprios 
indivíduos as suas escolhas e condutas. Elas são determinadas pelo grupo que as forjou, o que resulta em diferentes representações que estão relacionadas a uma multiplicidade de práticas, que resultam na construção de mundos sociais e identidades (CHARTIER, 1990, p. 17-18). Segundo R. Chartier, o estudo das representações:

[...] permite articular três modalidades da relação com o mundo social: em primeiro lugar, o trabalho de classificação e de delimitação que produz as configurações intelectuais múltiplas, através das quais a realidade é contraditoriamente construída pelos diferentes grupos; seguidamente, as práticas que visam fazer reconhecer uma identidade social, exibir uma maneira própria de estar no mundo, significar simbolicamente um estatuto e uma posição; por fim, as formas institucionalizadas e objetivadas graças às quais uns 'representantes' (instâncias coletivas ou pessoas singulares) marcam de forma visível e perpetuada a existência do grupo, da classe ou da comunidade (CHARTIER, 1990, p. 23).

Portanto, os textos presentes nos livros didáticos, expressam representações sobre o passado, e uma herança da produção historiográfica. E o livro didático História 3, dos autores Ronaldo Vainfas, Sheila de Castro Faria, Jorge Ferreira e Georgina dos Santos (2013), ao apresentar representações do passado, orienta a construção da consciência histórica dos jovens.

Ao analisar a organização dos assuntos no livro didático citado, percebe-se que o tema da Revolução Cubana é a quarta parte (VAINFAS et al., 2013, p. 147-149) do capítulo nove: "Construindo rivalidades: o mundo do pós-guerra II" (VAINFAS et al., 2013, p. 140). Também se identifica pelos títulos dos demais capítulos do volume, que foco é a história política dos Estados.

Ao iniciar a leitura do texto sobre a Revolução Cubana, a primeira informação colocada é a influência dos Estados Unidos na independência de Cuba e posteriormente nas políticas do Estado Cubano. O parágrafo seguinte informa sobre a ditadura de Fulgêncio Batista, na década de 1950, e o movimento dos estudantes da Universidade de Havana contra a ditadura. O segundo parágrafo é então concluído com o nome de Fidel Castro, identificado como líder estudantil. No parágrafo seguinte, o foco é o Movimento 26 de julho e o início do processo de construção da luta armada (VAINFAS et al., 2013, p. 147).

Observando a primeira página do texto, o foco da narrativa é a luta armada, na qual figuram os nomes de dois homens: Fidel Castro e Ernesto Che Guevara. O texto silencia a presença de mulheres no movimento estudantil, na organização do Movimento 26 de Julho (M-26) e na Guerrilha. Portanto, o texto reproduz a ideia 
presente na interpretação de Florestan Fernandes (FERNANDES, 2007), que coloca os dois homens como líderes do movimento de resistência e construtores da Revolução, pois somente os nomes de Ernesto Guevara e Fidel Castro aparecem no livro didático. Essa memória também é influenciada por Richard Gott (2006), obra referenciada no livro didático. Para R. Gott (2006), esses homens também são os líderes da Revolução Cubana, mas o autor também apresenta uma rede de relações - pessoas e movimentos constituídas contra a ditadura de Batista. Essa representação é percebida na parte do texto que informa sobre o início da Revolução. Segundo o livro didático:

Em 26 de julho de 1953, Fidel, com 26 anos de idade, liderando um grupo de 150 homens, atacou o quartel Militar de Moncada. O objetivo era derrubar Batista. [...] Em 1955, Fidel foi para o México organizar outra revolta. Ele liderava uma organização política, o Movimento Revolucionário 26 de Julho (MR-26). Um médico argentino de 27, Ernesto 'Che' Guevara, integrou-se ao grupo (VAINFAS et al., 2013, p. 147).

Ao construir essa narrativa, o texto reproduz o esquecimento da participação das mulheres na Revolução Cubana e se refere a acontecimentos que marcaram o processo de luta armada em Cuba, como espaços de homens. O ataque ao quartel de Moncada, em 26 de julho de 1953, em Santiago de Cuba, fato que marca o início do processo de luta armada na Revolução Cubana, o qual teve a participação de diversas mulheres na organização da ação e duas delas participação diretamente da ação, Haydée Santamaria e Melba Hernandes (SCHACTAE, 2016, p. 207), é apresentado como um acontecimento construído por homens. A organização do desembarque dos guerrilheiros, vindos do México, no ano de 1956, foi tarefa de Célia Sanchez (SCHACTAE, 2016), cujo nome também é silenciado. Ao se referir ao ano de 1958, o autor foca no controle do Estado pelo M-26 e silencia a participação do Pelotón Mariana Grajales, um grupo de mulheres guerrilheiras que atuava no M-26, combatendo na luta armada no Oriente de Cuba (SCHACTAE, 2016).

Ao se referir a relação entre os guerrilheiros e os movimentos sociais, os autores afirmam que:

Os guerrilheiros refugiados nas montanhas receberam apoio político, alimentos e armas enviados por lideranças de partidos e movimentos sociais das cidades. Com a adesão e o apoio que receberam, Fidel e seus homens se sentiram fortes para formar quatro colunas militares e derrubar o governo de Batista (VAINFAS et al., 2013, p. 147)

A narrativa novamente afirma a guerrilha e Fidel como centro do processo 
revolucionário. Os outros são apoiadores, não são agentes de transformação e não possuem nomes. Só os homens que encarnam a figura do guerrilheiro viril são nomeados, Fidel e Che Guevara.

O foco nos líderes expressa um saber que é apropriado pelos jovens na escola e em outros espaços sociais. Esse saber orienta a construção de consciência histórica, que é caracterizada por saberes generificados. Para Jorn Rüsen (2001) as apropriações dos estudantes sobre o passado são expressões da consciência histórica, pois para ele "a consciência histórica é a realidade a partir da qual se pode entender o que a história é, como ciência, e por que ela é necessária” (RÜSEN, 2001, p. 56).

Os heróis e símbolos da Revolução Cubana, apresentados nesse livro didático são homens barbudos e com armas, imagem presente na fotografia que aparece na primeira página (VAINFAS et al., 2013, p. 147). A escolha desta fotografia contribui para legitimar a representação da Revolução Cubana, presente no texto e na legenda da fotografia, que afirma: “em 4 de janeiro de 1959, dias após a vitória da revolução, Fidel Castro discursa ao lado de membros do Movimento Revolucionário 26 de julho" (VAINFAS et al., 2013, p. 147).

Focando na edição do ano de 2016, verifica-se uma alteração no título do capítulo 9, que é: "O mundo na Guerra Fria: entre conflitos mundiais e a luta por direitos" (VAINFAS et al., 2016, p.141). Na parte sobre a Revolução Cubana, foram retirados alguns parágrafos, porém, o núcleo central da narrativa é igual ao presente na edição de 2013. Inclusive as imagens, que são duas, permanecem as mesmas. Na primeira página aparece a fotografia citada anteriormente, embora apresente algumas diferenças.

A fotografia de janeiro de 1959, foi ampliada e recortada na edição de 2016 (VAINFAS et al., 2016, p.148), pois a bandeira de Cuba, que está na frente do palanque foi retirada. Nela figuram mais de quinze homens, seis dos quais estão em primeiro plano, entre os quais Fidel Castro. Apenas dois não vestem fardas e nitidamente é perceptível três homens com fuzis, posicionados no primeiro plano, ao lado esquerdo de Fidel Castro, que está no centro, discursando. Ao lado direito de Fidel está o Comandante Almeida, o único comandante negro da guerrilha, e atrás dele aparece a única mulher, visível na fotografia. Ela é Célia Sanchez, que também está usando a farda com o bracelete escrito " 26 de Julio", portanto, ela fazia parte da guerrilha. A legenda da fotografia também foi alterada, mas a ideia central permanece - "Fidel Castro discursa ao lado de membros do Movimento" (VAINFAS et al., 2016, p. 148). 
Essa imagem novamente legitima uma narrativa que o espaço de poder da Revolução Cubana é para de homens fardados e viris. Porém, a presença de uma mulher também indica que pode ser um espaço para mulheres fardadas e viris, mas somente o líder possui nome.

Para Peter Burke (2004, p. 223) nos estudos de imagens é importante observar as inscrições que algumas imagens trazem, pois o objetivo desses textos escritos é direcionar a leitura do espectador. No entanto na legenda da foto e no texto do capítulo, observa-se um silêncio sobre essa mulher. E um olhar pouco atento é absorvido pela imagem dos homens barbudos. Todavia, os autores e autoras do manual utilizaram como referência a obra de Richard Gott (2006), que apresenta quatro mulheres que atuaram no processo revolucionário, embora o autor coloque os homens como protagonistas. Portanto, elas (Célia Sanchez, Vilma Espin, Haydée Santamaria e Aleida March) poderiam aparecer no texto, principalmente porque é utilizada uma fotografia que indica a participação feminina, na luta armada.

A segunda imagem, também de uma fotografia de 1959, mostra populares com cartazes (VAINFAS et al., 2016, p. 149), e é a mesma presente na edição de 2013 (VAINFAS et al., 2013, p. 148). Porém, ela foi ampliada e recortada. A legenda possui o mesmo núcleo central, que afirma: "cubanos apoiam as primeiras medidas do governo de Fidel Castro" (VAINFAS et al., 2016, p. 149).

Observando a fotografia, no primeiro plano figuram homens sem barbas e duas mulheres jovens, que aparecem no canto esquerdo da imagem, uma delas é quase imperceptível. Chama a atenção do observador o cartaz que está no centro da fotografia, que afirma: venceremos. A questão que se coloca é: quem venceu nas representações dessas duas imagens? Claramente quem venceu foram os homens, pois eles figuram na narrativa escrita e na fotográfica. As mulheres, embora presentes nas duas imagens, só são percebidas por um observador atento ou uma observadora atenta.

Para Clifford Geertz, o sentido de uma imagem é resultado das "experiências coletivas" (GEERTZ, 2006, p. 165), que é a cultura. Portanto, o estudo das imagens é uma compreensão dos símbolos que produzem o cotidiano de seres humanos, isto é o contexto no qual foram produzidas (GEERTZ, 2006, p. 179-181). O silêncio sobre a imagem das mulheres revela uma herança cultural ocidental que ainda tende a tornar as mulheres invisíveis em determinados espaços sociais.

Um olhar atento, sobre o texto do livro didático analisado, indica uma reprodução das relações de poder generificadas, sendo o Estado e o espaço da guerra 
apresentados como exclusividade de homens viris e centrais para compreender a Revolução Cubana. Além do silêncio da presença de mulheres nesses espaços, o ideal de masculinidade, apresentado pelos heróis símbolos da Revolução Cubana, ressignificam um ideal de virilidade, presente na longa duração. E, no início do século XXI, o texto do livro didático analisado tende a reproduzir uma construção do herói, do espaço da luta armada e da política como domínio de homens, preferencialmente viris. Uma construção constatada por outros estudos sobre masculinidades e virilidades (CORBIN, 2013; SIERRA MADERO, 2005; SCHACTAE, 2013; MOREIRA, 2015; BONINO, 2002; STONER, 2003; OLAVARRIA, 2001; CONNEL, 2005).

Para além das armas e da guerra, é importante colocar que a vida cotidiana, as construções simbólicas, as escolas - e outros espaços sociais -, são constituídas por relações generificadas, além de orientar a reprodução dessas relações, pois funcionam como instrumento pedagógico. Sendo assim, o discurso historiográfico e do livro didático podem reproduzir relações de poder e silenciar sujeitos históricos, cabendo aos profissionais do campo da História ter um olhar crítico sobre a historiografia e os manuais didáticos.

O saber histórico construído em diferentes espaços de conhecimento e aprendizado precisa ser transformador da realidade. Construir uma consciência história a partir dessa representação da Revolução Cubana, é uma forma de reproduzir as relações de poder. A atuação política de estudantes, artistas, mulheres e homens que não estiveram na guerrilha, mas que atuaram em vários movimentos nas cidades e nos campos de Cuba, foi silenciada. Assim como, foram silenciadas as mulheres guerrilheiras, mesmo diante de ampla produção sobre estudos de gênero, no Brasil atual.

A representação construída tende a reproduzir um discurso historiográfico político que exclui as mulheres, colocando a guerrilha, Fidel Castro e Che Guevara como centrais no processo revolucionário. Também identifica alguns espaços e acontecimentos como centrais para compreender o professo revolucionário, escolhas que legitimam o mito da guerrilha - o ataque ao Quartel Moncada, o desembarque do Granma, a Sierra Maestra, o Movimento 26 de Julho.

Portanto, o exercício de olhar para as representações da Revolução Cubana deve ser estendido para os acontecimentos do passado, narrados nos livros didáticos de História. É preciso dar voz e visibilidade aos silenciados da História. Todavia, ainda é necessário aprofundar as análises das narrativas sobre a Revolução Cubana, observando os textos de outros livros didáticos e comparando as narrativas. 
As narrativas presentes no livro didático analisado orientam para a construção de uma consciência histórica que reproduz um ideal de virilidade, colocando os sujeitos identificados como herdeiros desse ideal, Fidel Castro (advogado) e Che Guevara (médico), como centrais na construção da Revolução Cubana. Portanto, a história desse processo histórico apreendida pelos estudantes que utilizam esse livro didático, tende a reproduzir uma narrativa que coloca a guerra e os homens viris como construtores dos processos históricos, reafirmando um construção do passado que silencia o outro, aqueles e aquelas que não reproduzem o ideal viril do guerrilheiro rebelde. Homens brancos, vestindo uniforme militar, com curso superior e barbudo, são aqueles que fazem a história, são os guias e os salvadores, essa é uma ideia que tende a ser reproduzida nas representações acerca da Revolução Cubana.

\section{Referências}

ADAO, Rafael; SANTOS, Julio Cesar. A Revolução Cubana em livros didáticos de ensino médio. Revista Labirinto, Porto Velho-RO, ano XV, Vol. 22, p. 127-143, 2015.

ALDERETE, Matías. Masculinidad revolucionaria: la represión de maricones y la construcción del hombre nuevo en Cuba pos-revolucionaria. In: X Jornadas de Sociología. Facultad de Ciencias Sociales, Universidad de Buenos Aires, Buenos Aires, 2013.

AUDOIN-ROUZEAU, Stéphane. Exércitos e guerras: uma brecha no coração do modelo viril? In: CORBIN, Alain; COURTINE, Jean-Jacques; VIGARELLO, Georges. História da Virilidade - A virilidade em crise? Séculos XX-XXI. Petrópolis, RJ: Vozes, p. 239-268, 2013.

AYERBE, Luis Fernando. A Revolução Cubana. São Paulo: UNESP, 2004.

BARDIN, Laurence. Análise de conteúdo. São Paulo: Edições 70, 2011.

BEAUDIEU, Sarah. Política cultural y periodismo em Cuba: trayctorias cruzadas de la prensa oficial y de los medios independientes (1956-2013). Tese (Doutorado em Literatura), Universidad de Granada, Granada, 2013. Disponível em: https://hera.ugr.es/tesisugr/23574264.pdf. Acesso em: 13 jul. 2020.

BONINO, Luis. Masculinidad hegemónica e identidad masculina. Dossiers feministes, v. 6, p. 7-36, 2003.

CHARTIER, Roger. A história cultural: entre práticas e representações. Lisboa: DIFEL, 1990.

CHOMSKY, Aviva. História da Revolução Cubana. São Paulo: Veneta, 2015. 
CONNELL, R. W. Políticas da masculinidade. Educação e realidade. v. 20, n. 2, 2005, p. 185-206.

COURTINE, Jean-Jacques. Impossível virilidade. In: CORBIN, Alain; COURTINE, Jean-Jacques; VIGARELLO, Georges. História da Virilidade - A virilidade em crise? Séculos XX-XXI. Petrópolis, RJ: Vozes, 2013.

CUERVO ALVAREZ, Benedicto. Cuba: su difícil camino hacia la independencia (1845-1898). La Razón Histórica, n³4, 2016, p. 73-110. Disponível em: www.revistalarazonhistorica.com. Acesso em: 07 jul. 2020.

DEPARTAMENTO DE ORIENTACIÓN REVOLUCIONARIA DEL COMITÉ CENTAL DEL PARTIDO COMUNISTA DE CUBA. Seleccion de discursos - Fidel Castro/Raúl Castro. La Habana, Editora Política: 1978.

ESCALONA RODRÍGUEZ, Norberto. Maianas: nobleza y coraje. La Habana, Cuba: Consejo de Estado, 2018.

FERNANDES, Florestan. Da guerrilha ao socialismo: a Revolução Cubana. São Paulo: Expressão Popular, 2007.

GIRARDET, Raoul. Mitos e Mitologias políticas. Companhia das Letras, SP. 1987.

GRAÑA EIRIZ, Manuel. Clandestinos en prisión. La Habana: Editorial de Ciencias Sociales, 2008.

GROTT, Richard. A Revolução de Castro toma forma (1953-1961). In: uma nova história. Rio de Janeiro: Zahar, 2006, p. 171-217.

GUEVARA, Ernesto Che. Una historia de la revolucion cubana, Revista O Cruzeiro, 1959. Disponível em: Web del Centro Estudios "Miguel Enríquez", CEME, http://www.archivo-chile.com. Acesso em: 05 jan. 2018.

GUEVARA, Ernesto. O socialismo e o homem em Cuba. Semanário Marcha, Montevideo, Março de 1965. Disponível em: www.marxists.org. Acesso em: 03 jan. 2018.

ILISÁSTIGUI AVILÉS, Margarita; ÁLVAREZ PORRO, Gladys. Melba: mujer de todos los tiempos. La Havana: Ediciones Verde Olivo, 2005.

LEYVA PAGÁN, Georgina. História de una gesta libertadora 1952-1958. La Habana: Editorial de Ciencias Sociales, 2009.

LOPEZ, Francisca; LOYOLA, Oscar; SILVA, Arnaldo. Cuba y su historia. La Habana; Editorial Felix Varela, 2005.

MISKILIN, Sílvia Cezar. Cultura ilhada: imprensa e Revolução Cubana (1959-1961). São Paulo: Xamã, 2003. 
MOREIRA, R.; SCHACTAE, A.; SOTO, I. Sónõra. Entre guerrilleras, soldados y policias: lo femenino en instituciones armadas de Cuba y de Brasil. In: MARTINS; A.; GUEVARA, M. Politicas de Gênero na América Latina: aproximações, diálogos e desafios, Jundiaí: Paco Editorial, 2015, p. 141-170.

PAGÉS, Julio César Gonzalez. La Republica Femenina: Organizaciones Revolucionarias de Mujeres 1952-1958. Universidade de Havana: Havana, 1991.

PEREZ ROJAS, Niurka. El movimiento estudantil universitario de 1934 a 1940. La Habana: Editorial de Ciencias Sociales, 1975.

RAMONET, Ignacio. Cien Horas con Fidel. La Habana, Cuba: Oficina de Publicaciones del Consejo de Estado, 2006.

RÉMOND, René. Do político. In: (org.). Por uma história política. Rio de Janeiro: Editora FGV, 2003, p. 441-450.

RÜSEN, Jörn. O livro didático ideal. In: MARTINS, Estêvão; Schmidt, Maria Auxiliadora (Orgs.). Jörn Rüsen e o ensino de história. Curitiba: Ed. da UFPR, 2010, p. 109-127.

RÜSEN, Jörn. Razão histórica. Brasília: Editora UNB, 2001.

SCHACTAE, Andréa. Mulheres Guerreiras: mulheres na guerrilha cubana e a construção da heroína Célia Sanchez. In: MOREIRA, Rosemeri; SCHACTAE, Andréa (org.). Gênero e instituições armadas. Guarapuava, PR: Editora Unicentro, 2016, p. 189-215.

SCOTT, J. Gênero: uma categoria útil de análise história. Educação e Realidade, n. 20, vol. 2, p.71-99, 1995.

SCOTT, J. W. Prefácio a Gender and Politics of History, Cadernos Pagu, no 3, 1994, p. 11-27.

SIERRA MADERO, Abel. Del otro lado del espejo. La sexualidad en la construcción de la nación cubana. La Habana: Editorial Casa de las Américas, 2006.

STONER, K. L. Militant heroines and the consecration of the patriarchal state: the glorification of loyalty, combat, and national suicide in the making of Cuban National Identity. In: Cuban Studies, volume 34, 2003, pp. 71-96. Disponível em: http://muse.jhu.edu/jounals/cub/summary/v034/34.1stoner01.html. Acesso em: 20 de dez. 2010.

VAINFAS, Ronaldo; FARIA, Sheila de Castro; FERREIRA, Jorge; SANTOS, Georgina dos. História 3. São Paulo: Saraiva, 2013.

História 3. São Paulo: Saraiva, 2016.

Artigo recebido em 04 de agosto de 2020. Aprovado em 30 de novembro de 2020. 